\title{
Metallated Schiff-Base Macromolecules as Alternative Metalloprotein Electron Transfer Intermediates
}

\author{
Al C. Farao, Rachel Fanelwa Ajayi, Meryck Ward, Priscilla GL Baker \\ SensorLab Research Group, Department of Chemistry, University of the Western Cape, PB X17, Bellville, South Africa \\ Email: pbaker@uwc.ac.za
}

How to cite this paper: Farao, A.C., Ajayi, R.F., Ward, M. and Baker, P.G. (2020) Metallated Schiff-Base Macromolecules as Alternative Metalloprotein Electron Transfer Intermediates. Journal of Surface Engineered Materials and Advanced Technology, 10, 34-54.

https://doi.org/10.4236/jsemat.2020.102003

Received: November 26, 2019

Accepted: April 27, 2020

Published: April 30, 2020

Copyright $\odot 2020$ by author(s) and Scientific Research Publishing Inc. This work is licensed under the Creative Commons Attribution International License (CC BY 4.0).

http://creativecommons.org/licenses/by/4.0/

(c) (i) Open Access

\begin{abstract}
In the construction of biosensors, enzymes function as mediators converting biological signals generated by specific biological processes, into electrochemical signals. The ideology of bio-sensor design is retention of electron transfer activity of the enzyme utilizing superior interfacial architecture. In this work a Schiff-base macromolecule has been synthesized by reflux of 2 , 3-diaminonaphthalene and pyrrole-2-carboxaldehyde starting materials. The Schiff-base ligand was subsequently complexed with $\mathrm{FeCl}_{2} \cdot 4 \mathrm{H}_{2} \mathrm{O}$ under reflux, to produce the Fe-Schiff-base complex. The Schiff-base ligand and Fe-Schiff-base complex were characterized using nuclear magnetic resonance (NMR) spectroscopy, Ultra Violet/Visible (UV/Vis) spectroscopy, Fourier transfer infrared resonance (FTIR) and electron energy loss spectroscopy (EELS) to confirm the structure of the synthesis products. NMR spectroscopy confirmed the imide linkage of Schiff-base formation as two symmetrical peaks at 8.1 and $7.7 \mathrm{ppm}$ respectively. Comparison of starting materials and product spectra by UV/Vis spectroscopy confirmed the disappearance of the diaminonaphthalene peak at $250 \mathrm{~nm}$ as evidence of complete conversion to product. FTIR spectroscopy of the Schiff-base ligand confirmed the formation of the imine bond at $1595 \mathrm{~cm}^{-1}$. EELS spectra comparing $\mathrm{FeCl}_{2} \cdot 4 \mathrm{H}_{2} \mathrm{O}$ and the Fe-Schiff-base complex, showed good agreement in the energy loss profiles associated with changes to the electronic arrangement of Fe d-orbitals. EDS clearly identified a spectral band for $\mathrm{Fe}(7-8 \mathrm{eV})$ in the Fe-Schiff-base complex. Electrochemical evaluation of the Fe-Schiff-base complex was compared to the electrochemical signature of denatured cytochrome-C using cyclic voltammetry and square wave voltammetry. The $\mathrm{Fe}^{2+} / \mathrm{Fe}^{3+}$ quasi-reversible behavior for iron in the metallated complex was observed at $-0.430 \mathrm{~V}$ vs. $\mathrm{Ag} / \mathrm{AgCl}$, which is consistent with reference values for iron in macromolecular structures.
\end{abstract}




\section{Keywords}

Cytochrome-C, Macromolecule, Metallated, Metalloproteins, Schiff-Base

\section{Introduction}

Horse heart cytochrome-C presents a very simplistic structural design consisting of 104 amino acids and is often utilized as a prototype for metalloproteinase [1] [2]. Cytochrome-C serves as an electron shuttle, by forming reversible complexes with its redox counterparts during electron transfer [3].

The active site in cytochrome- $\mathrm{C}$ is the iron heme that is covalently linked to the enzyme at cys 14 and cys 17 by thioether bonds. During the electron transfer process the redox state of the iron changes between $\mathrm{Fe}^{2+} / \mathrm{Fe}^{3+}$.

The iron heme lies in the plain of a porphyrin ring [4], of which the $5^{\text {th }}$ and $6^{\text {th }}$ sites are occupied by the nitrogen of the imidazole ring of histidine. Bonanni et al., (2003) investigated the adsorption of cytochrome-C molecules from yeast on bare gold electrodes [5]. Methodologies for fixing these proteins to an electrode surface without affecting the integrity of the protein made up a major component of the research. The results indicated that yeast cytochrome- $\mathrm{C}$, directly self-chemisorbed onto the gold electrode, retained its morphology and redox properties, with coverage of up to $84 \%$ of the electrode substrate. Electron transfer limitations for immobilized cytochrome-C could also be overcome by the application of a monolayer surface modifier [5]. This method promotes electron transfer by orientating the molecules to a fixed and electronically favorable orientation [5].

The electron charge transfer of cytochrome-C is difficult to detect on bare electrodes. Bond et al., (1992) investigated the mass transport mechanisms associated with redox processes of cytochrome-C at gold electrodes modified with 4 , 4'-bipyridyl disulphide (SS-bpy). They concluded that modifier layers provide electro active sites under applied potential. They ascribed the improvements to the modifiers unblocking parts of the electrode surface by displacing adsorbed cytochrome-C providing sites for electron transfer [6]. Heat treatment induces functional changes to the structure of the heme of cytochrome-C, His-Fe-Met octahedral coordination and a thioether bond with two cysteine residues of the peptide chain. The peptide chain of hemoglobin or myoglobin bound only the histidine residue as a fifth ligand resulting in unfolding of the peptide chain, to expose the Fe heme as the methionine-sulphur coordination disappeared. Consequently the heme becomes exposed to water, resulting in the heme's newly acquired autoxidation ability.

Eguílaz et al., (2010) constructed a cytochrome-C based biosensor by drop-coating cytochrome-C on a hybrid glassy carbon electrode modified with poly-(3-methylthiophene) and multiwall carbon nanotubes [7]. The hybrid GCE was coated with a self-assembled monolayer of 1-cysteine onto 
which cytochrome-C was drop coated. The system was evaluated against $\mathrm{H}_{2} \mathrm{O}_{2}$, as cytochrome-C type biosensors have been used for the determination of $\mathrm{H}_{2} \mathrm{O}_{2}$ and other analytes related to $\mathrm{H}_{2} \mathrm{O}_{2}$ quantification [8] [9]. The sensor displayed good performance in the amperometric determination of $\mathrm{H}_{2} \mathrm{O}_{2}$. When used in the biocatalytic determination of nitrite the system displayed superior sensitivity.

Electrostatic or chemisorptive end-capping of proteins with gold nanoparticles has been reported to improve distant donor-acceptor electronic coupling [10] [11] [12] [13]. In a study by Caban, Offenhäusser and Mayer (2009) bovine heart cytochrome- $\mathrm{C}$ was electrostatically coupled to an atomically flat $\mathrm{Au}$ (111) surface through a monolayer of 11-mercaptoundecanoic acid. Binding of the gold nanoparticles to cytochrome-C was identified with AFM to proceed via two mechanisms [14], based on changes in magnitude of the redox response. It was postulated that the attachment of the nanoparticles might have caused substantial deformation of the protein's ternary structure resulting in increased heme-electrode distance. The redox response of the system was related to immobilization time of the particles and their size. Binding of the Au nanoparticles were found to favorably alter the spatial geometry of cytochrome-C by accelerating the long range electron transfer rate of the protein [14]. Tanimura et al., (2002) reported on modifying the electrode surface with a self-assembled monolayer of alkanethiols. The positively charged lysine residues subsequently aligned with the negatively charged carboxylate head group, enhancing the electron transfer capabilities [15].

In this work, we endeavor to reproduce the redox chemistry of the iron heme of denatured cytochrome-C whilst circumventing the complexities associated with functionalizing cytochrome- $\mathrm{C}$ for sensor application. The heme structure was emulated by synthesizing a Schiff-base ligand and complexing it with iron. The electron transfer properties of the macrocycle were evaluated by means of voltammetry and compared to that of commercial denatured cytochrome-C modified Schiff-base.

\section{Experimental Section}

Starting materials, 2, 3-diaminonaphthalene and pyrrole-2-carboxaldehyde, were purchased from Sigma Aldrich and used without further purification. Propanol (Sigma) was dried over molecular sieves at room temperature. Dimethylformamide and $37 \% \mathrm{HCl}$ was purchased from KIMIX chemicals. $0.1 \mathrm{M} \mathrm{HCl}$ and $0.1 \mathrm{M}$ $\mathrm{NaBF}_{4}$ supporting electrolyte solutions were prepared with Millipore deionized water from a Millipore Synergy water system with a resistivity of $18 \mathrm{M} \Omega$.

The Schiff-base was synthesized through the condensation reaction between 2, 3-diaminonaphthalene and pyrrole-2-carboxaldehyde under anhydrous conditions in propanol. The reaction was initiated by dissolving the amine, 2, 3-diaminonaphthalene, in dried propanol. In a separate vessel pyrrole-2-carboxaldehyde was dissolved in dried propanol and heated prior to addition to ensure dissolution. The dissolved aldehyde was added drop-wise to the 
amine. The reaction was performed under reflux at $60^{\circ} \mathrm{C}$. The reaction progress was monitored with thin layer chromatography on silica plates in 90:10 ratio hexane ethanol mobile phase. At hour 72 the reaction reached completion [16].

Schiff-base reactions are nucleophilic substitution reactions which are generally either acid, base or heat catalyzed. The acidic nature of the aldehyde pyrrole-2-carboxaldehyde negated the need for additional acid catalysis. Acidic catalysis activate the carbonyl carbon for nucleophilic attack. The 2, 3-diaminonaphthalene acts as a weak nucleophile due to steric hindrance. The carbinolamine produced is a tetrahedral intermediate and unstable, which undergoes acid catalyzed dehydration [17]. Condensation reactions are trademarked by the production of water, which in turn impacts on reversibility of the reaction. Therefore it was imperative to keep reaction conditions free of water.

${ }^{\mathrm{H}} \mathrm{NMR}$ spectra were recorded on a Bruker BioSpin $\mathrm{GmbH} 300$ in $\mathrm{CDCl}_{3}$. FTIR analysis was performed on PerkinElmer spectrophotometer over the range of 400 to $4000 \mathrm{~cm}^{-1}$. $4 \mathrm{mg}$ sample aliquots were mixed with dried $\mathrm{KBr}$ and compressed into pellets with a PerkinElmer $\mathrm{KBr}$ pellet quick press. Starting materials and ligand product were prepared as $100 \mu \mathrm{g} / \mathrm{L}$ samples for UV/Vis absorbance, measured on a Nicolet Evolution 100 UV/Vis spectrophotometer, over the 200 to $900 \mathrm{~nm}$ spectral range with $10 \mathrm{~mm}$ pathlength Hellma absorption cuvettes in ethanol.

Electron Microscopy, for EELS analysis, required $\mathrm{FeCl}_{2} \cdot 4 \mathrm{H}_{2} \mathrm{O}$ and Fe-Schiff-base complex to be coated directly onto $\mathrm{Cu}$ stubs and sputter coated with activated carbon. Analysis was performed on a new Field Emission Tecnai F20. High resolution SEM coupled to EDS analysis was performed on a Zeiss Auriga EMU.

Electrochemical experiments were performed on the PalmSens potentionstat using DropSens screen-printed carbon electrodes. The ligand and the Fe-Schiff-base complexes were electrodeposited onto the screen printed carbon electrodes with cyclic voltammetry in the range $-0.6 \mathrm{~V}$ to $0.7 \mathrm{~V}$ (vs. $\mathrm{Ag} / \mathrm{AgCl}$ ) for five cycles. The stability of the Fe-Schiff-base complex was evaluated by cycling in phosphate buffer electrolyte solution $\mathrm{pH} 7$, from -1 to $1 \mathrm{~V}$ at scan rates 10,50 and $100 \mathrm{mVs}^{-1}(\mathrm{n}=3)$. Spectrometric analysis was conducted on all three electrolyte solutions to identify leaching of iron into the solution

\section{Results and Discussion}

Schiff-base synthesis. The Schiff-base N, N-bis (1H-pyrrole-2yl) methylene naphthalene-2, 3-diamine was synthesized by the condensation reaction of 2, 3-diaminonaphthalene and the acidic aldehyde pyrrole-2-carboxaldehyde (see Scheme 1).

The H NMR spectrum showed an absence of the characteristic amine and carbonyl chemical shift values expected for 2, 3 diaminonaphthalene and pyrrole-2-carboxaldehyde respectively. The spectrum of the Schiff-base produced showed two symmetrical peaks i.e. at 8.1 and $7.7 \mathrm{ppm}$ which was evidence of 


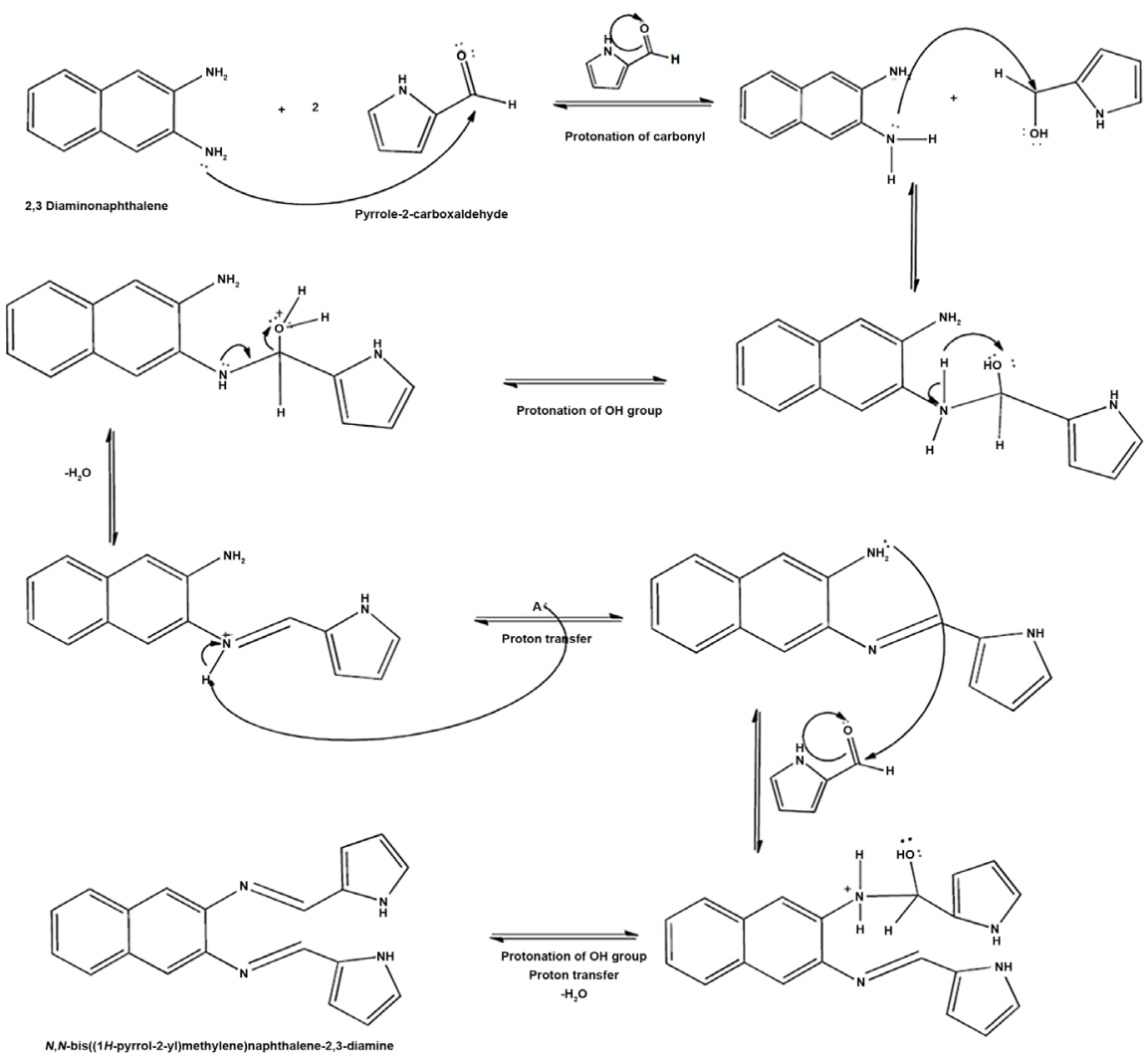

Scheme 1. Proposed mechanism for the preparation of Schiff-base ligand N, N-bis (1H-pyrrole-2yl) methylene naphthalene-2, 3-diamine.

imine formation (-N=CH-). These chemical shift values for the imine coincided with reported data by Simionescu et al., (1998) who synthesized and polymerized pyrrolylidene naphthylamine Schiff-base compounds.

Infrared analysis was performed on the starting materials as well as Schiff-base product (see Table 1). The spectra identified characteristic absorption bands for each compound. The FTIR spectrum of Schiff-base produced molecular vibrations and rotations that were a combination of 2, 3-diaminonaphthalene and pyrrole-2-carboxaldehyde. 2,3-Diaminonaphthalene identified an absorption band at $3380 \mathrm{~cm}^{-1}$ which coincided with reports in literature for primary amines [18]. The absorption band at $1595 \mathrm{~cm}^{-1}$ coincided with literature reports and confirmed the formation of the Schiff-base through the formation of the imine bond [19] [20]. The shift in the wavelength coincided with findings in literature. The spectra of the ligand also indicated the absence of the $\mathrm{C}=\mathrm{O}$ shift at 1633 $\mathrm{cm}^{-1}$ [16]. Extending pi conjugation has been reported by Wei et al., (2002) to result in a red shift. The study investigated the effect of pi conjugation on the properties of boron difluoride [21]. A theoretical study by Bonanni et al., (2003) on the effects of substituents, such as cyano and carbonyl groups on pyrrole, found these groups to have an effect on the HOMO and LUMO levels [22]. The groups were found to decrease the band gap and increase the conjugation length of the polymers which impacts absorbance. In the spectra of the Schiff-base similar shifts in stretching vibrations were evident for the pyrrole ring. 
Table 1. FTIR bands relevant to N, N-bis (1H-pyrrole-2yl) methylene naphthalene-2, 3-diamine characteristics.

\begin{tabular}{cc}
\hline Wavelength, $\mathrm{nm}$ & Assignment \\
\hline $3380-3300$ & $1^{\circ}$, diaminonaphthalene \\
3150 & $\mathrm{~N}-\mathrm{H}$ group, pyrrole \\
1633 & $\mathrm{C}=\mathrm{O}$ carbonyl, \\
1595 & Imine \\
\hline
\end{tabular}

Distinctly different UV spectra were obtained for pyrrole-2-carboxaldehyde, 2, 3-diaminonaphthalene and Schiff-base product. For the product three bands were detected at 230, 288 and $349 \mathrm{~nm}$. The bands at $230 \mathrm{~nm}$ and $288 \mathrm{~nm}$ were attributed to the $\pi-\pi^{*}$ transitions of the aromatic rings of pyrrole and naphthalene. The absorption band at $349 \mathrm{~nm}$ was attributed to the $\pi-\pi^{*}$ of the imine [23] (Figure 1).

When the spectrum of the product was compared to the starting materials changes in the peak height, shape and size was evident. Peak broadening was observed for the Schiff-base that was evidence of extended conjugation. The absorption band in the region of 275 to $300 \mathrm{~nm}$ for the Schiff-base was assigned to $\mathrm{n}-\pi$ transition in the aromatic rings. The absorption band at $350 \mathrm{~nm}$ for the Schiff-base was assigned to $\pi-\pi^{\star}$ in the aromatic ring and $C=N$ [20] [24]. The diaminonaphthalene starting material peak recorded at $250 \mathrm{~nm}$ was absent in the Schiff-base product.

Infrared analysis was performed on the starting materials and the monomer, and compared as per Figure 2. The results identified a spectra with characteristic absorption bands for each compound. N, N-bis(1H-pyrrole-2yl)methylene naphthalene-2,3-diamine identified molecular vibrations and rotations that were a combination of 2,3-diaminonaphthalene and pyrrole-2-carboxaldehyde. 2,3-Diaminonaphthalene identified an absorption band at $3380 \mathrm{~cm}^{-1}$ which coincided with reports in literature for primary amines [18]. The absorption band at $1595 \mathrm{~cm}^{-1}$ coincided with literature reports, and confirmed the formation of the Schiff-base which was characterized by formation of an imine bond [18] [19] [20]. The shift in the wavelength coincided with findings in literature. Extending pi conjugation has been reported by Barbon, Staroverov and Gilroy (2015) resulted in red shifts [21]. The study investigated the effect of pi conjugation on the properties of boron difluoride. The study found pi conjugation to have a direct impact on wavelength absorption which resulted in a red shift. Isaiah, Adejoro and Collins (2013) found substituents, such as cyano and carbonyl groups on pyrrole, to have an effect on the HOMO and LUMO levels [22]. Subsequently, the Schiff-base product was used as the ligand for complexation with Fe under reflux.

Fe complex synthesis: The macromolecule was synthesized by refluxing a 5 $\mathrm{mM}$ methanolic solution of the metal precursor $\left[\mathrm{FeCl}_{2} \cdot 4 \mathrm{H}_{2} \mathrm{O}\right]$ in a $10 \mathrm{mM}$ methanolic solution of the monomer. The solution was heated to $60^{\circ} \mathrm{C}$ and 


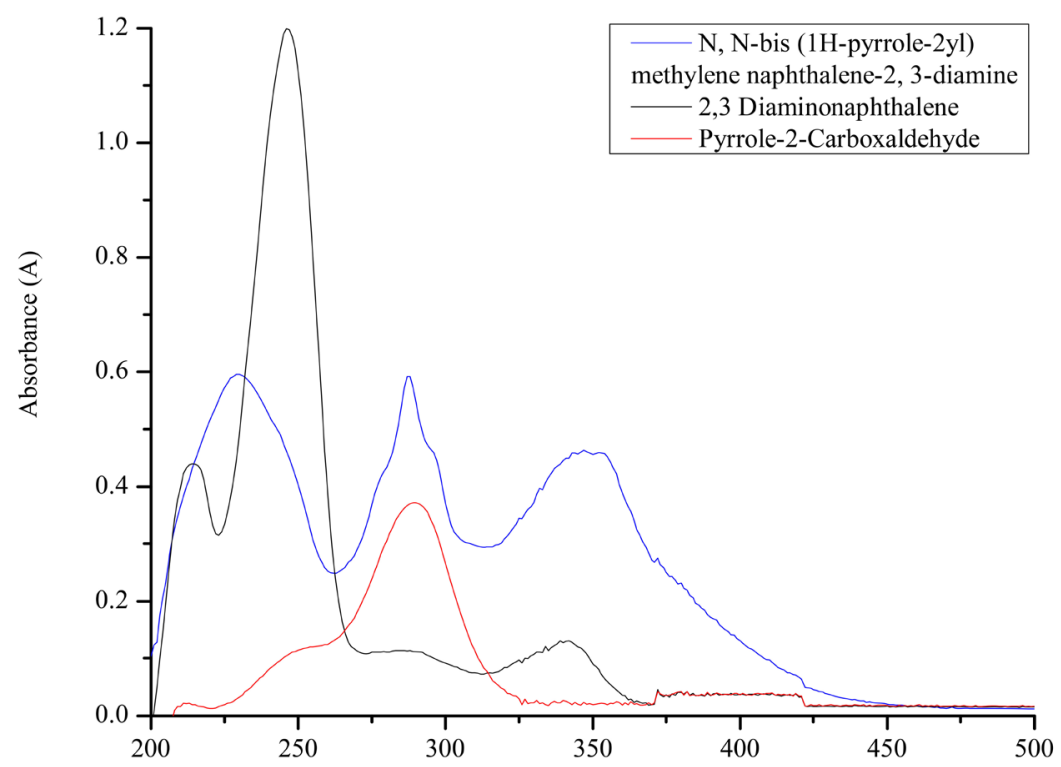

Figure 1. UV/Vis absorbance of starting materials 2, 3-diaminonaphthalene, pyrrole-2-carboxaldehyde and synthesized product $\mathrm{N}, \mathrm{N}$-bis $(1 \mathrm{H}$-pyrrole-2yl) methylene naphthalene-2, 3-diamine (Schiff-base) in ethanol.

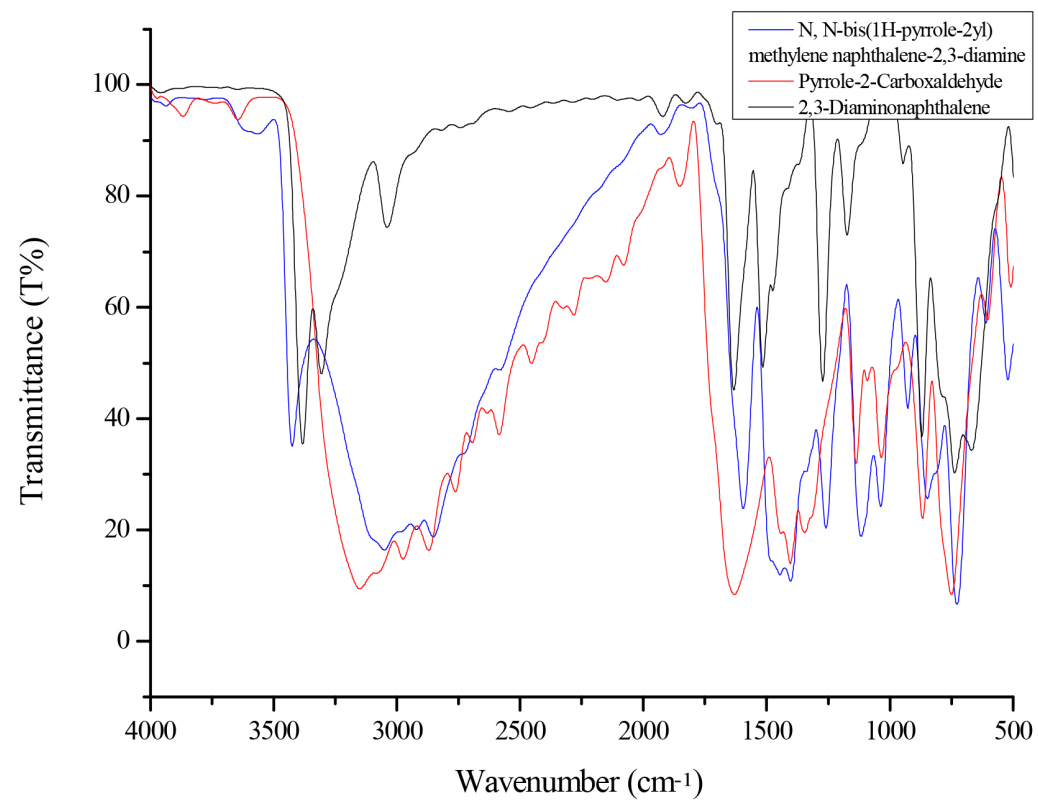

Figure 2. FTIR spectra of starting materials 2,3-diaminonaphthalene, pyrrole-2-carboxaldehyde and monomer N, N-bis(1H-pyrrole-2yl)methylene naphthalene-2,3-diamine in dried $\mathrm{KBr}$.

refluxed for three hours after which a dark coloured precipitate was obtained. At the 30 minute mark there was a colour change of the solution from red brown to black. Scheme 2 predicts a possible mechanism and structure for the macromolecule based on the iron chelating and ligand binding effect of $\mathrm{N}, \mathrm{N}-$ bis $(1 \mathrm{H}$-pyrrole-2yl)methylene naphthalene-2,3-diamine. Pyrrole in a study by Doddi et al., (1976), who investigated the reactivity of pyrrole in nucleophilic 


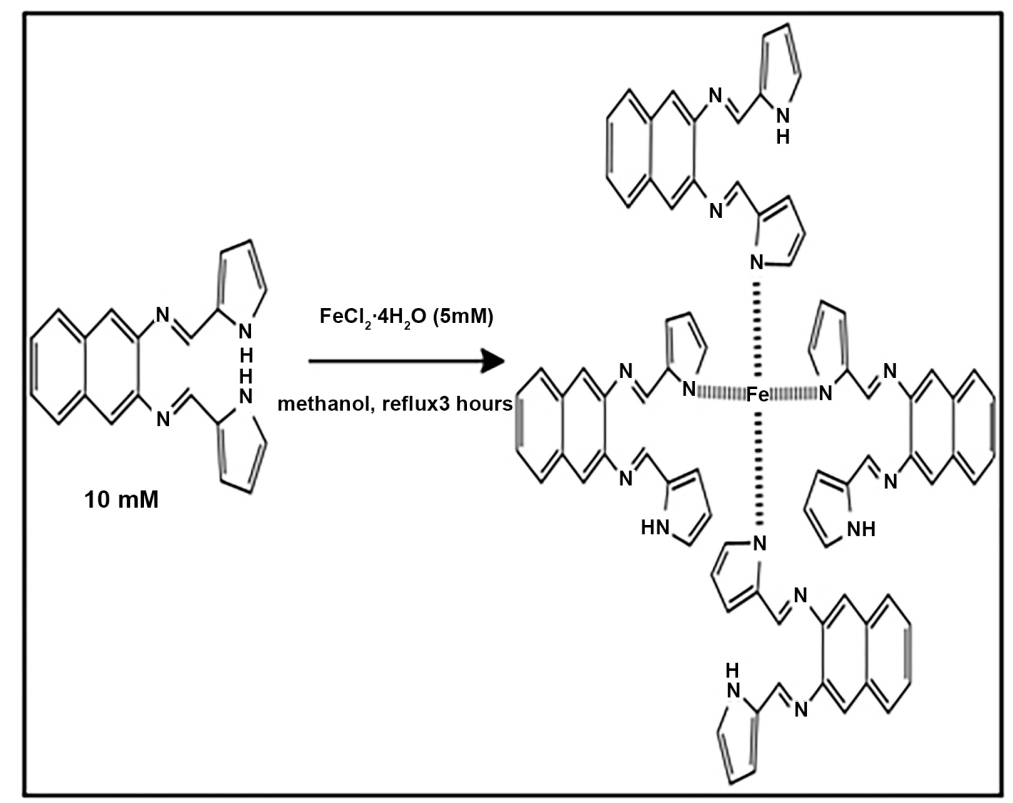

Scheme 2. Proposed mechanism for the preparation of the macromolecule.

substitution in comparison to furan and thiophene derivatives, found pyrrole to be not as reactive relative to the other heteroatoms [25]. Ligands with soft-donor atoms prefer iron (II), such as nitrogen containing ligands [26]. This predicate suggested the metal to ligand binding between the pyrrole lone pair and iron. The higher the number of chelating rings attached to the chelator the higher the stability [26]. A square planar coordination with four ligands chelated to $\mathrm{Fe}$ was proposed. It offered substantial electronic stabilization. Strong field ligands have been reported to adopt square planar geometry in $\mathrm{Ni}$ complexes. Square planar coordination for iron (II) compounds have been reported to be limited to complexes containing porphyrin, salicylaldimato, phthalocyanine ligands [27]. Based on the premise of $\mathrm{N}, \mathrm{N}$-bis (1H-pyrrole-2yl) methylene naphthalene-2, 3-diamine being a heterocyclic macrocycle organic compound it was deduced that the macromolecule would adopt square planar geometry.

FTIR analysis of the Fe-Schiff-base ligand complex is presented in Figure 3. The spectra showed a shift in frequency for some ligand bands and also identified a new band $473 \mathrm{~cm}^{-1}$ which was attributed to metal ligand complexation [28] [29] [30]. This band was absent in the unbound ligand. The azomethine (imine bond) vibrational stretch was recorded at $1595 \mathrm{~cm}^{-1}$, for the ligand. According to literature a shift toward lower frequency would have been recorded if the iron complexed through the azomethine nitrogen, and a shift to higher frequency would indicate shortening bond length [31] [32] [33]. Evidence suggests that the metal ligand coordination did not proceed via the imine linkage, since a shift to higher frequency was recorded for the azomethine group at $1630 \mathrm{~cm}^{-1}$. This shift confirmed that the iron did not complex with the azomethine group and complexation occurred at the pyrrole nitrogen. The broad peak at $3200 \mathrm{~cm}^{-1}$ was evidence that one of the 2 pyrrole units retained an uncomplexed nitrogen, for each ligand binding to the Fe centre [32]. 


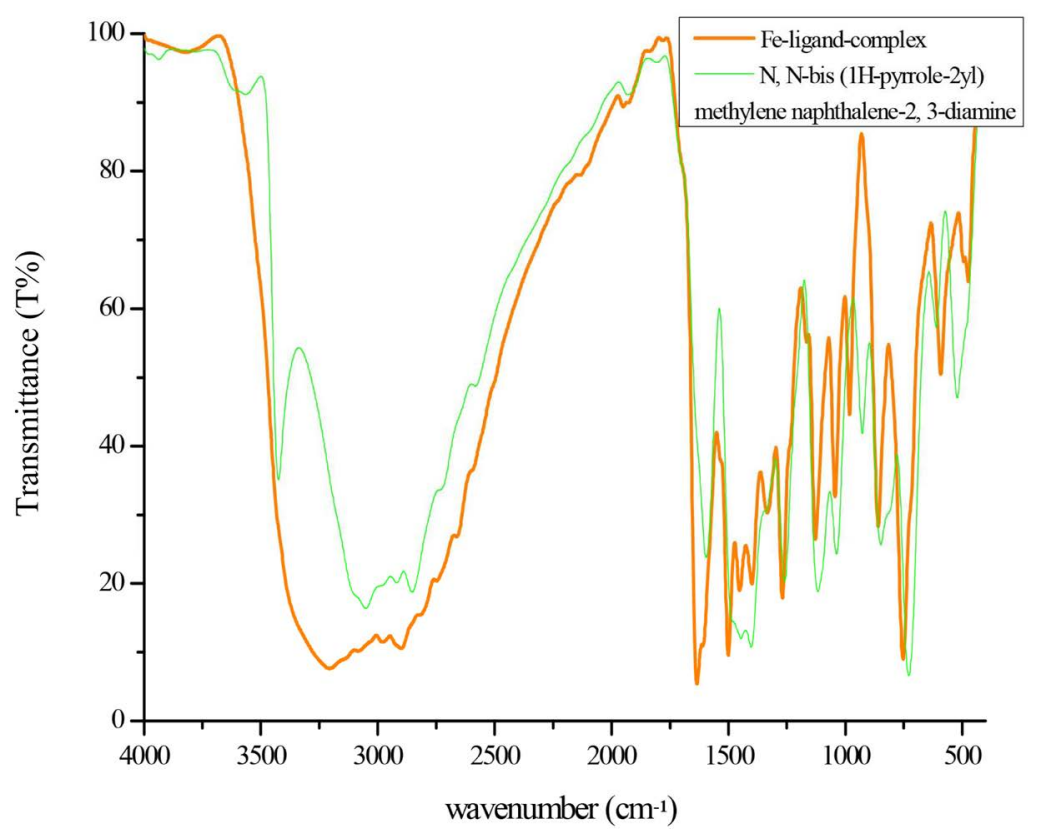

Figure 3. FTIR spectra of the Schiff-base ligand and Fe-Schiff-base ligand complex prepared as dried $\mathrm{KBr}$ pellets.

The UV/Vis spectra of the Fe-Schiff-base ligand complex was measured and compared with that of the ligand N, N-bis (1H-pyrrole-2yl) methylene naphthalene-2, 3-diamine as presented in Figure 4. The Fe-Schiff-base ligand complex produced three absorption peaks at 225, 287 and $350 \mathrm{~nm}$, respectively. The peaks at $225 \mathrm{~nm}$ and $287 \mathrm{~nm}$ were attributed to the $\pi-\pi^{*}$ transitions in the aromatic rings of pyrrole and naphthalene. The absorption band at $350 \mathrm{~nm}$ can be attributed to the $\pi-\pi^{*}$ of the imine. When the spectra of the Fe-Schiff-base ligand complex was compared to the ligand a narrowing of the bands were evident. These changes were attributed to the coordination with iron. The spectrum identified weak absorbance above $400 \mathrm{~nm}$ which could be the $\mathrm{d}$-d transitions of the metal but the intensity of the transitions were too weak to be conclusive on its own [34].

Transition electron microscopy (TEM) was performed on the ligand and the Fe-Schiff-base ligand complex. The samples were sputter coated onto copper grids for analysis.

In Figure 5 and Figure 6 the high resolution TEM micrographs shows the structural morphology of the ligand (Figure 5) and Fe-Schiff-base ligand complex (Figure 6). The morphology of the Fe-Schiff-base ligand complex (Figure 6) appears more structured following chelation with iron. In order to confirm successful coordination of iron to the monomer (N, N-bis (1H-pyrrole-2yl) methylene naphthalene-2, 3-diamine) electron energy loss spectroscopy (EELS) was performed on the Fe-Schiff-base ligand complex as well as the starting material $\mathrm{FeCl}_{2} \cdot 4 \mathrm{H}_{2} \mathrm{O}$. The EELS spectrum in Figure 7 of the Fe-Schiff-base ligand complex provided an absolute measurement of iron in the complex. Transition metals exhibit L3 and L2 edges which is an expression of the excitations of electrons from $2 p$ to unfilled $3 \mathrm{~d}$ orbitals. The orbital transitions are represented by ratios. 


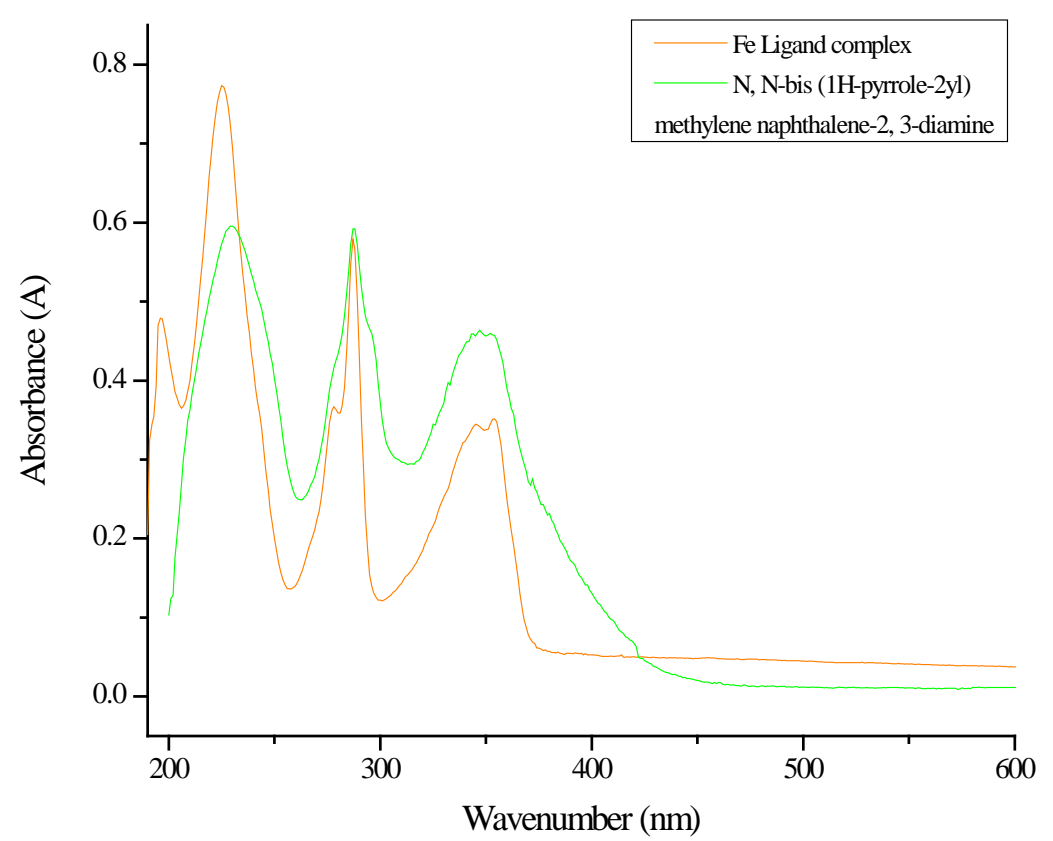

Figure 4. UV/Vis spectroscopy of the $\mathrm{N}, \mathrm{N}$-bis (1H-pyrrole-2yl) methylene naphthalene-2, 3-diamine and Fe-Schiff-base ligand complex in ethanol 1 $\mathrm{mg} / \mathrm{ml} 100 \times$ dilution.

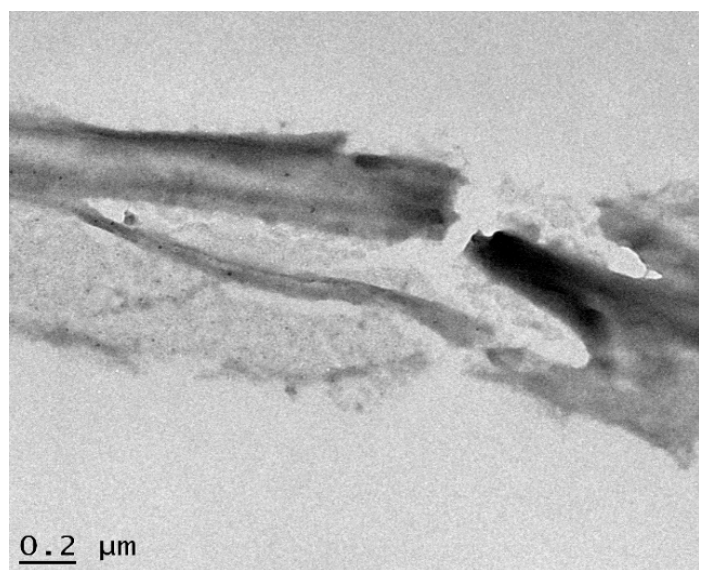

Figure 5. TEM micrographs of the ligand.

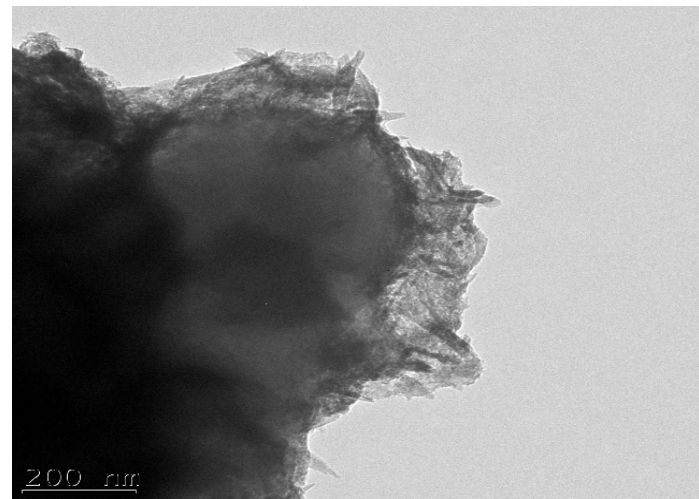

Figure 6. TEM micrographs of Fe-Schiff-base ligand complex. 


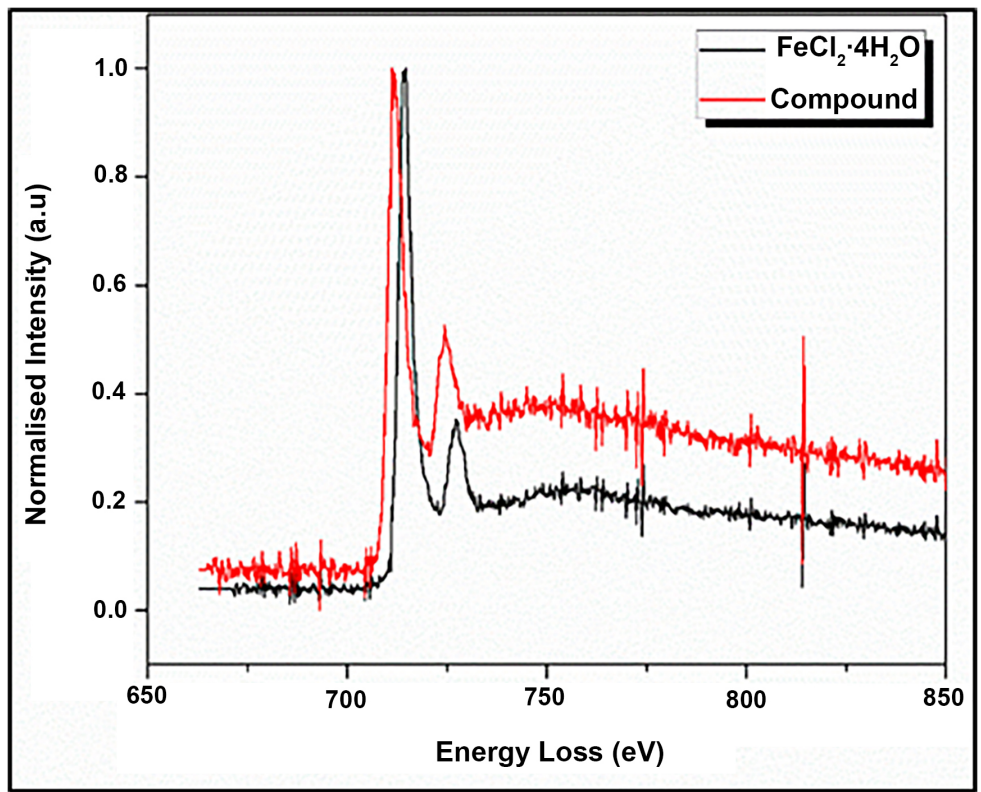

Figure 7. EELS analysis of $\mathrm{FeCl}_{2} \cdot 4 \mathrm{H}_{2} \mathrm{O}$ (black curve) vs Fe-Schiff-base ligand complex (red curve).

Variations in L3/L2 intensity ratios are related to changes to the electronic structure of the d orbitals. In order to monitor changes in the L3/L2 intensity ratios of the iron EELS was performed on Fe-Schiff-base ligand complex as well as the iron precursor (see Figure 7). Analysis of the results revealed a change in the peak ratios. Changes to the peak ratios would be evidence of a change in electron density surrounding the iron [35] [36]. Based on these findings coordination of iron to the monomer was confirmed. EELS also revealed iron to remain in the $\mathrm{Fe}^{2+}$ oxidation state with almost similar energy-loss spectra to that of $\mathrm{FeCl}_{2} \cdot 4 \mathrm{H}_{2} \mathrm{O}$.

EDS analysis was performed on the Fe-Schiff-base ligand complex to confirm the presence of iron in the complex (see Figure 8 and Figure 9). The results showed no iron was present in the ligand (Figure 8) but present in the Fe-Schiff-base ligand complex (Figure 9).

Electrochemical experiments. Denatured cytochrome-c $(1 \mathrm{mg} / \mathrm{mL}$ stock solution) was electrodeposited directly onto a bare SPCE by cycling from $-0.600 \mathrm{~V}$ to $0.700 \mathrm{~V}$ at $50 \mathrm{mV} / \mathrm{s}$. The Schiff-base ligand was electrodeposited onto a SPCE in the same way, starting from a $5 \mathrm{mM}$ equivalent of the ligand solution, prepared by dissolving $(5 \mathrm{mM}) \mathrm{N}, \mathrm{N}$-bis $(1 \mathrm{H}$-pyrrole-2yl) methylene naphthalene-2,3-diamine dissolved in dimethylformamide $0.1 \mathrm{M} \mathrm{NaBF}_{4}$ mixed electrolyte system. Cyclic voltammetry was used to deposit the ligand onto the working electrode, by cycling the potential between $-600 \mathrm{mV}$ to $700 \mathrm{mV}$ for 5 cycles.

Scan rate dependent studies were done using cycling voltammetry varying the scan rate from $10 \mathrm{mV} / \mathrm{s}$ to $500 \mathrm{mV} / \mathrm{s}$ in the potential window $-1 \mathrm{~V}$ to $1 \mathrm{~V}$.

In the forward scan a non-reversible oxidation process was recorded producing a peak at $0.687 \mathrm{~V}$ vs $\mathrm{Ag} / \mathrm{AgCl}$ (Figure 10). The oxidation process at $0.687 \mathrm{~V}$ was a one electron transfer process, electrochemical in nature, that produced $\mathrm{Ph}=\left[\mathrm{NHC}_{5} \mathrm{H}_{7} \mathrm{~N}\right]^{+}$, an unstable intermediate [34] [35] [37]. The anionic radical, 


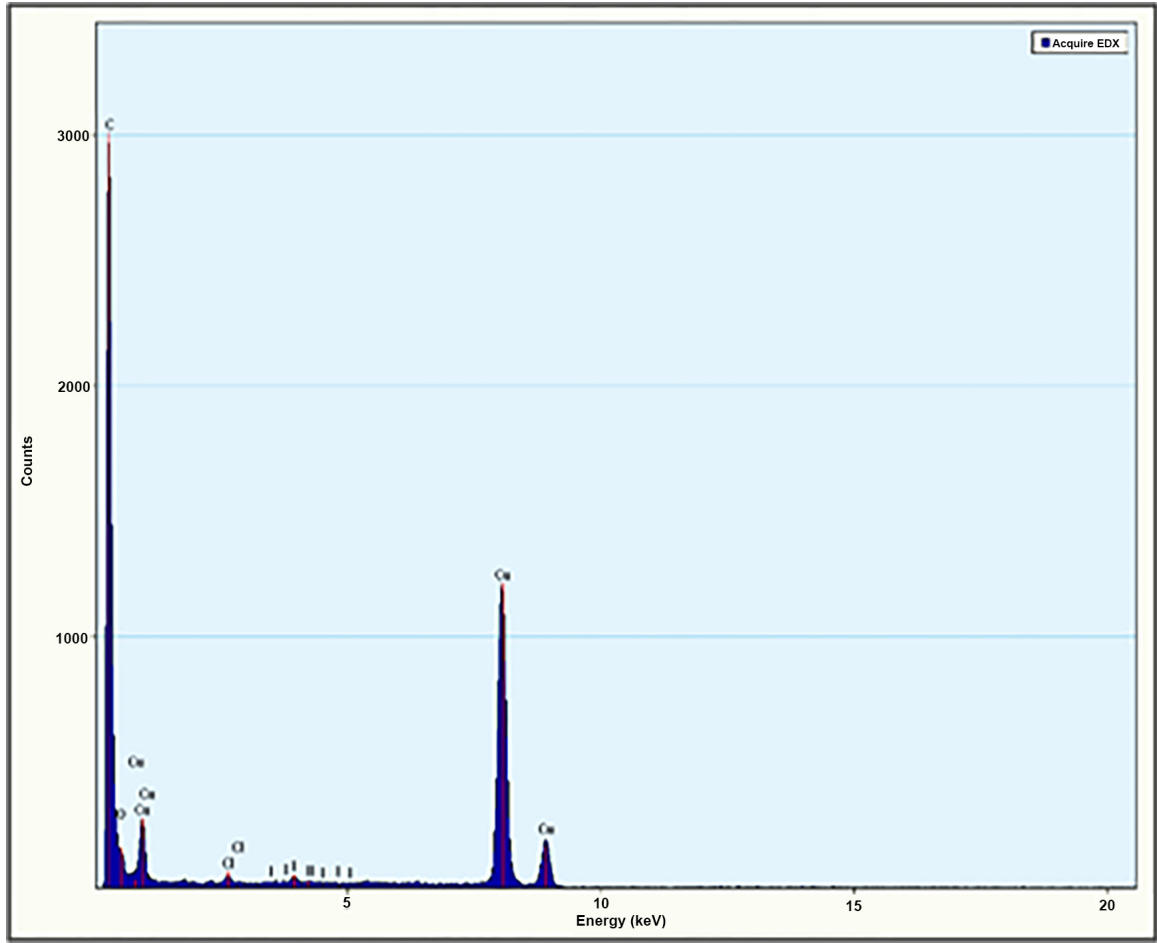

Figure 8. Energy-Dispersive X-ray Spectroscopic (EDS) analysis of Schiff-base ligand.

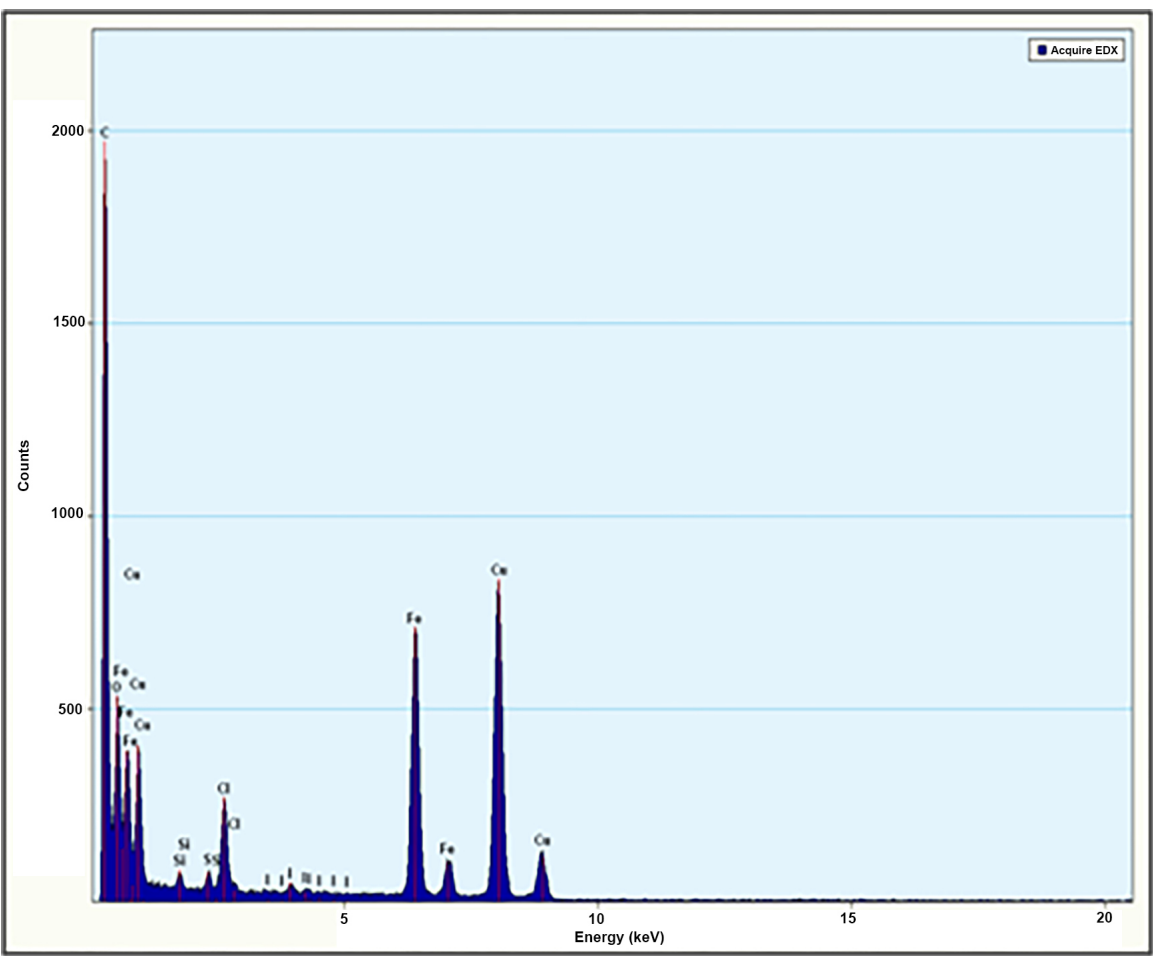

Figure 9. Energy-Dispersive X-ray Spectroscopic (EDS) analysis of Fe-Schiff-base ligand complex.

was reduced on the reverse scan and a strong reduction peak was observed at $-0.676 \mathrm{~V} \mathrm{Vs} \mathrm{Ag} / \mathrm{AgCl}$ in the cathodic scan [38]. At $10 \mathrm{mV} / \mathrm{s}$ the peak to peak 


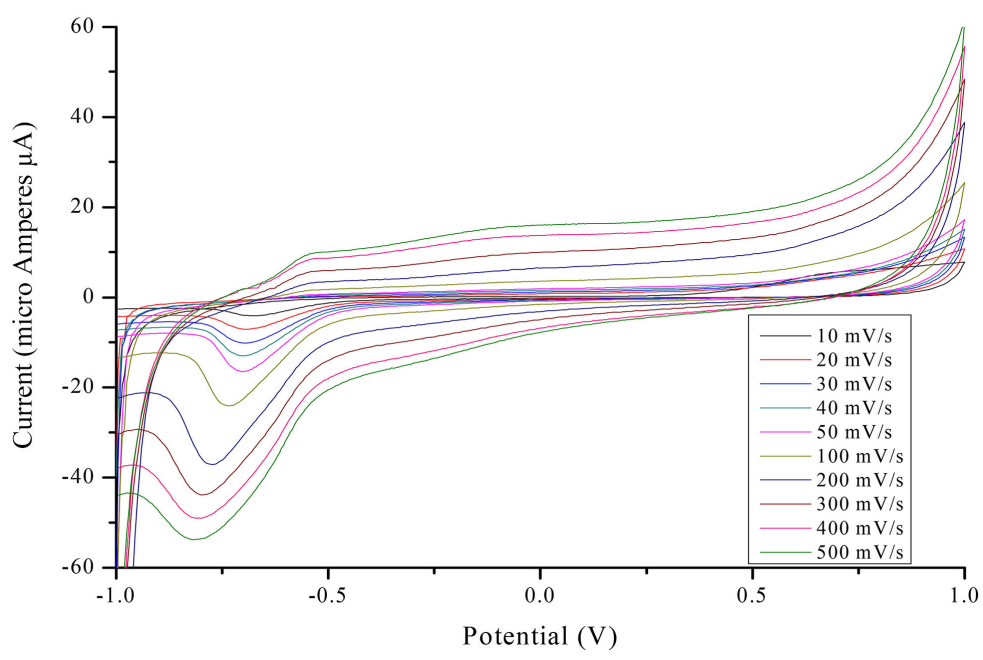

Figure 10. Cyclic voltammetry of SPCE modified with Schiff-base ligand, in $0.1 \mathrm{M}$ PBS vs $\mathrm{Ag} / \mathrm{AgCl}$ electrode at scan rates $10 \mathrm{mV} / \mathrm{s}$ to $500 \mathrm{mV} / \mathrm{s}$ in the potential window -1 to $1 \mathrm{~V}$.

separation was calculated at $\Delta \mathrm{E}=1.36 \mathrm{~V}$ and the electron transfer process was determined to be non-reversible.

At higher scan rates the electron transfer in the system changed from non-reversible to poorly defined quasi-reversible, based on peak separation values. The peak current behavior in response to changes in scan rate indicated adsorption behavior during the oxidation waves and diffusion controlled electron transfer during the reduction waves, recorded [39].

Denatured cytochrome-C was coated onto a bare SPCE (Figure 11(a)) and compared to cytochrome-C coated onto the Schiff-base ligand modified SPCE (Figure 11(b)). An irreversible anodic peak was recorded at $0.420 \mathrm{~V}$ for denatured cytochrome-c deposited onto the bare SPCE (Figure 11(a)) which was attributed to $\mathrm{Fe}$ oxidation in denatured cytochrome. Lysine has been reported to facilitate redox processes within the enzyme but high temperature denaturation deprotonates lysine. This results in changes in the redox behaviour of the enzyme [40] [41]. For the ligand modified SPCE onto which denatured cyto-chrome-C was drop coated, a quasi-reversible redox couple was recorded at $-0.524 \mathrm{~V}$ vs $\mathrm{Ag} / \mathrm{AgCl}$ at $10 \mathrm{mV} / \mathrm{s}$ consistent with $\mathrm{Fe}^{2+} / \mathrm{Fe}^{3+}$ redox behaviour in macromolecules. These findings coincided with reports in literature. Sagara et al., (1990) found electron transfer reactions to be facilitated by surface modifiers in their investigation of the behaviour of cytochrome-C deposited on gold electrodes modified with 4-pyridyl derivatives [42]. Similar findings were reported by Eddowes and Hill (1979), when investigating the impact of monolayers on the electron transfer behaviour of cytochrome-C. The ligand modified SPCE drop-coated with denatured cytochrome-C (Figure 11(b)) displayed oxidizing potentials more negative than denatured cytochrome-c on bare SPCE with reversible electron transfer behavior (Figure 11(a)).

Diffusion controlled electrochemical processes, typically follow Randle-Sevçik 


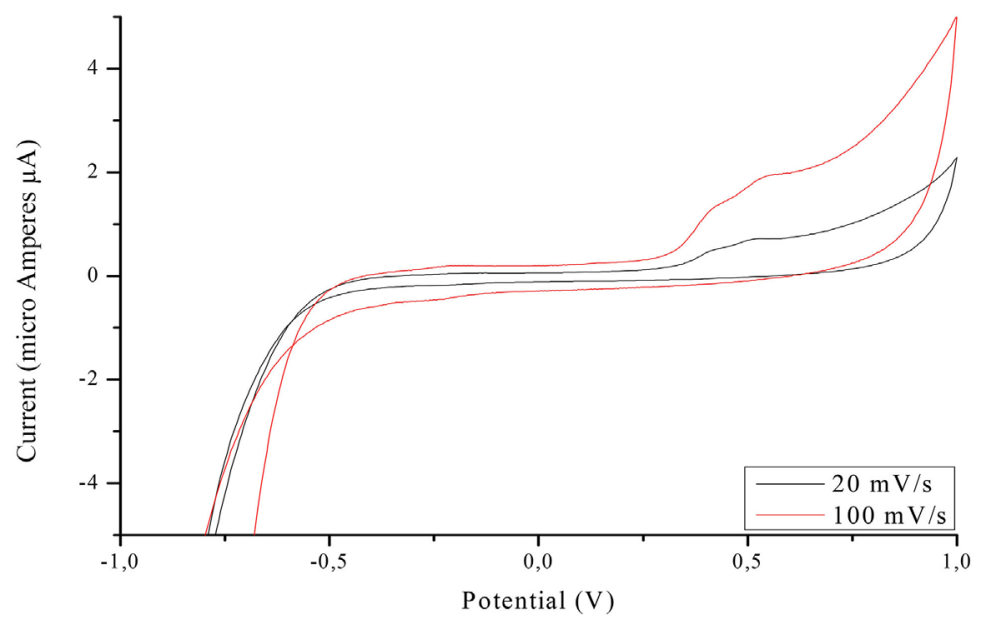

(a)

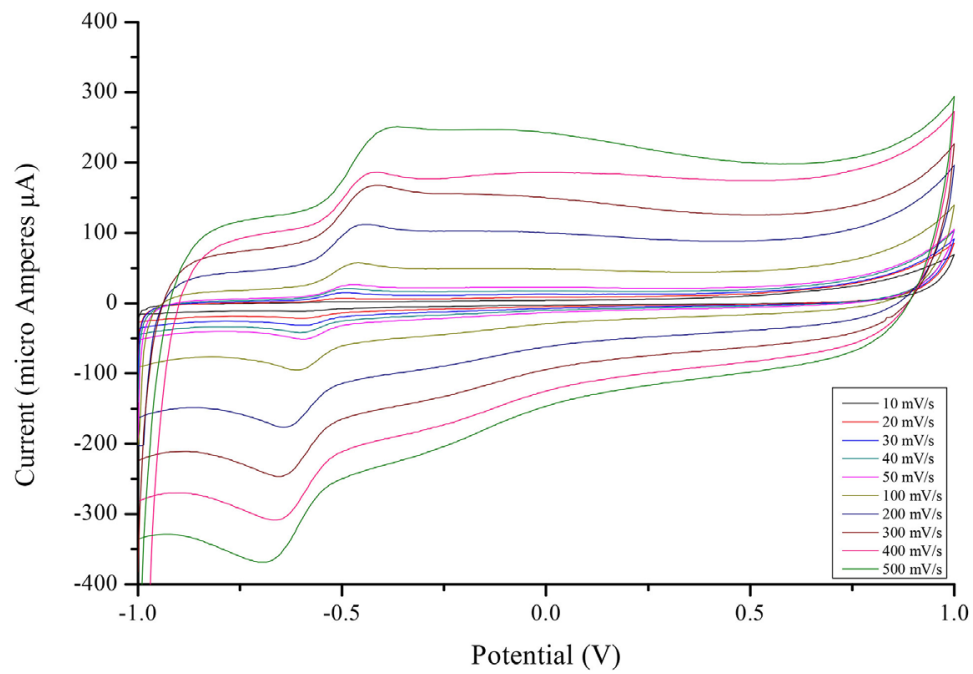

(b)

Figure 11. (a) Cyclic voltammetry of SPCE modified with denatured cytochrome-C (b) Ligand modified SPCE onto which denatured cytochrome- $C$ was drop-coated in 0.1 M PBS vs $\mathrm{Ag} / \mathrm{AgCl}$ electrode at scan rates $10 \mathrm{mV} / \mathrm{s}$ to $500 \mathrm{mV} / \mathrm{sin}$ the potential window -1 to $1 \mathrm{~V}$.

kinetics according to equation, $I p=(2.69 \times 105) n \frac{3}{2} A D_{e} \frac{1}{2} C v \frac{1}{2}$, where $(A)$ is the surface area, $\left(D_{e}\right)$ diffusion coefficient and $(C)$ analyte concentration. The systems displayed diffusion controlled kinetics as evidenced by the linear regression lines for scan rates $10-500 \mathrm{mV} / \mathrm{s}$. The diffusion coefficient $\left(D_{e}\right)$ was calculated to be $1.07 \times 10^{-6} \mathrm{~cm}^{2} / \mathrm{s}$ for the anodic process and $1.31 \times 10^{-6} \mathrm{~cm}^{2} / \mathrm{s}$ for the cathodic process. These values were in agreement with a report by Eddowes and Hill (1979). De values of $9.4 \times 10^{-7} \mathrm{~cm}^{2} / \mathrm{s}$ were reported for 4,4'-bipyridal cytochrome-c systems [43]. Abass and Hart (2001) reported De values of $8.1 \times 10^{-7}$ $\mathrm{cm}^{2} / \mathrm{s}$ for the anodic peak currents and $8.03 \times 10^{-7} \mathrm{~cm}^{2} / \mathrm{s}$ for the cathodic peak currents in their investigations of cytochrome-c deposited on polycarbonate modified SPCE [44]. 
Cyclic voltammetry was performed on the SPCE modified with the Fe-Schiff-base ligand complex. Cyclic voltammetry showed the system to be electroactive (Figure 12) in the electrochemical window $-1 \mathrm{~V}$ to $1 \mathrm{~V}$ vs $\mathrm{Ag} / \mathrm{AgCl}$. A well-defined redox couple was recorded at $-0.429 \mathrm{~V}$ vs $\mathrm{Ag} / \mathrm{AgCl}$. Coordination of $\mathrm{Fe}$ to the ligand system appeared to have shifted the potential at which oxidation and reduction occurred. In the forward scan an anodic peak was recorded at $-0.414 \mathrm{~V}$ and cathodic peak at $-0.507 \mathrm{~V}$ in the reverse scan.

Reference values for uncomplexed iron, are given as [45].

$$
\mathrm{Fe}^{2+}+2 \mathrm{e}^{-}=\mathrm{Fe}(\mathrm{s}) \text { at }+0.44 \mathrm{~V}
$$

and

$$
\mathrm{Fe}^{3+}+\mathrm{e}^{-}=\mathrm{Fe}^{2+} \text { at }-0.77 \mathrm{~V}
$$

However the values for $\mathrm{Fe}$ oxidation and reduction, when iron is complexed within a macromolecule structure, changes. Negative shifts in redox potentials, according to reports, is an indication of increased stability of Fe [46] [47]. This was highlighted for $\mathrm{Fe}$ in cytochrome- $\mathrm{C}$ in this work, and the redox potentials observed for the Fe-Schiff-base ligand complex was in good agreement with the redox potentials measured for cytochrome-C electrodeposited at the SPCE electrode, in the same way.

Diffusion coefficient values for the Fe-Schiff-base ligand complex deposited onto the SPCE were $8.86 \times 10^{-7} \mathrm{~cm}^{2} \cdot \mathrm{s}^{-1}$ for oxidation currents $\left(\mathrm{I}_{\mathrm{pa}}\right)$ and $9.38 \times 10^{-7} \mathrm{~cm}^{2} \cdot \mathrm{s}^{-1}$ for reduction currents $\left(\mathrm{I}_{\mathrm{pc}}\right)$. Compared to phenazine-2, 3-diimino (pyrrole-2-yl) (PPDP), a similar type hinge system, doped with 1, 4-naphtaquinone sulphonic acid (NQSA) and polyvinylsulfonic acid (PVSA) the diffusion rates were competitive. The following diffusion coefficient values for PPDP doped with NQSA were reported; De of $4.62 \times 10^{-7} \mathrm{~cm}^{2} \cdot \mathrm{s}^{-1}\left(\mathrm{I}_{\mathrm{pa}}\right)$ and $4.39 \times 10^{-7} \mathrm{~cm}^{2} \cdot \mathrm{s}^{-1}\left(\mathrm{I}_{\mathrm{pc}}\right)$. PDDP doped with PVSA on the other hand reported De values $9.28 \times 10^{-3} \mathrm{~cm}^{2} \cdot \mathrm{s}^{-1}\left(\mathrm{I}_{\mathrm{pa}}\right)$ and $1.60 \times 10^{-2}$ $\mathrm{cm}^{2} \cdot \mathrm{s}^{-1}\left(\mathrm{I}_{\mathrm{pc}}\right)$. Zaheer et al., (2011) investigated the introduction of ferrocene moieties into Schiff bases with De values of $2.66 \times 10^{-5} \mathrm{~cm}^{2} / \mathrm{s}^{-1}$ [46].

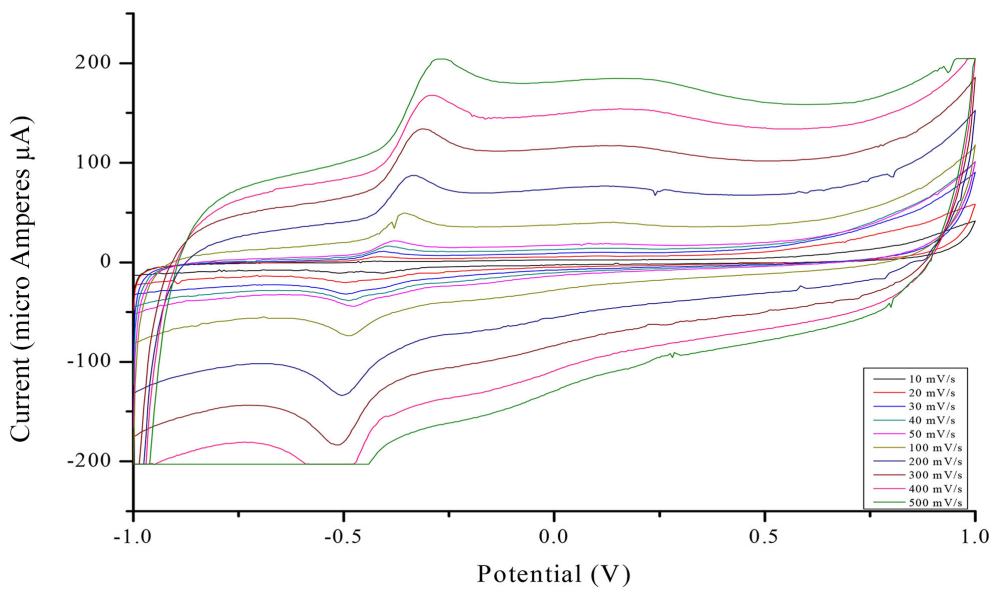

Figure 12. Cyclic voltammetry of SPCE modified with Fe-Schiff-base ligand complex in 0.1 M 0.1 PBS vs $\mathrm{Ag} / \mathrm{AgCl}$ electrode at scan rates 10 to $500 \mathrm{mV}$ over the potential window -1 to $1 \mathrm{~V}$. 
Comparing the diffusion coefficient values for the ligand, ligand modified with denatured cytochrome- $\mathrm{C}$ and Fe-Schiff-base ligand modified SPCEs, the presence of iron significantly impacted the electron transfer characteristics of the Schiff-base complex.

Stability of Fe-Schiff-base ligand complex modified electrode. The stability of the iron within the Fe-Schiff-base ligand complex modified electrode, under redox conditions, was evaluated. The Fe-Schiff-base ligand complex, deposited onto a SPCE, was connected as the working electrode in a 3 electrode arrangement and subjected to potential cycling in $0.1 \mathrm{M} \mathrm{PBS}$. CV analysis was conducted at three different scan rates $10 \mathrm{mV} / \mathrm{s}, 50 \mathrm{mV} / \mathrm{s}$ and $100 \mathrm{mV} / \mathrm{s}$ within the potential window $-1 \mathrm{~V}$ to $1 \mathrm{~V}$. UV/Vis absorbance measurements were subsequently performed on the electrolyte solutions, after each CV scan in order to identify the presence of $\mathrm{Fe}$ in the electrolyte solution as evidence of possible leaching of complexed iron during redox cycling. This experiment was performed in triplicate and labelled A, B and C.

Electrochemical analysis showed no changes to the redox chemistry of the Fe-Schiff-base ligand system (see Figures 13-15). The forward scan recorded an anodic peak current at $-0.566 \mathrm{~V}$ and cathodic peak current at $-0.636 \mathrm{~V}$ in the reverse scan. The cyclic voltammetric results showed no evidence of iron leaching into the solution.

$\mathrm{UV} / \mathrm{Vis}$ absorbance confirmed the presence of $\mathrm{Fe}$, only, after the initial scan (see Figure 16). However, in subsequent analysis no evidence of leaching could be observed. Upon continued cycling the subsequent electrolyte solutions were found to be free of Fe. The presence of Fe initially observed in the UV/Vis data was assigned to loosely bound residual material from the electrodeposition process.

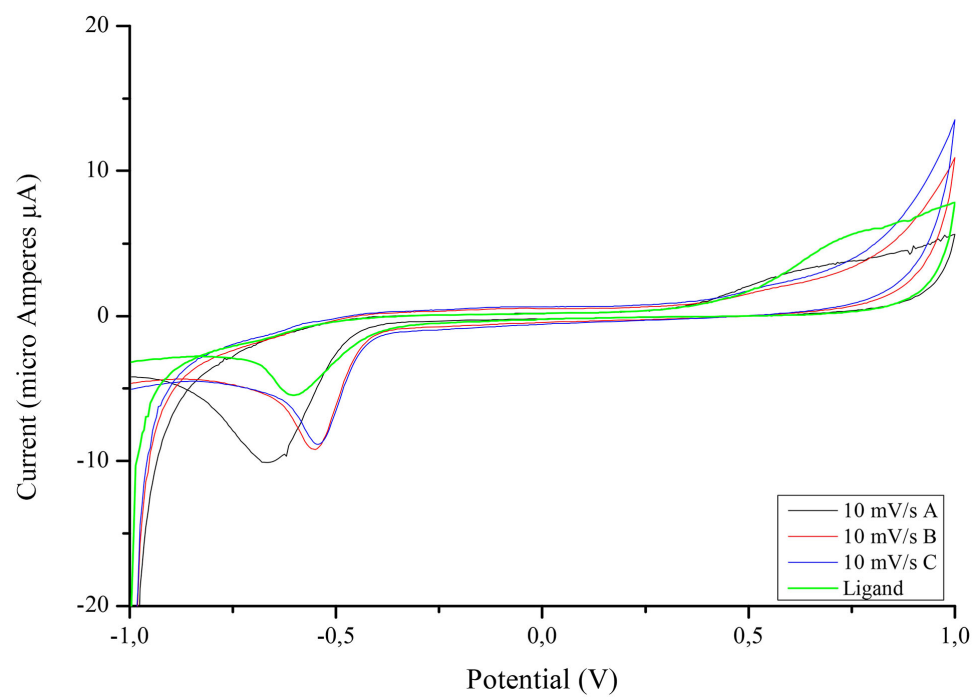

Figure 13. Cyclic voltammograms of the Fe-Schiff-base ligand complex electrodeposited onto a screen print carbon electrode in PBS at; performed at $10 \mathrm{mV} / \mathrm{s}$ for scans $\mathrm{A}, \mathrm{B}$ and $\mathrm{C}$. 


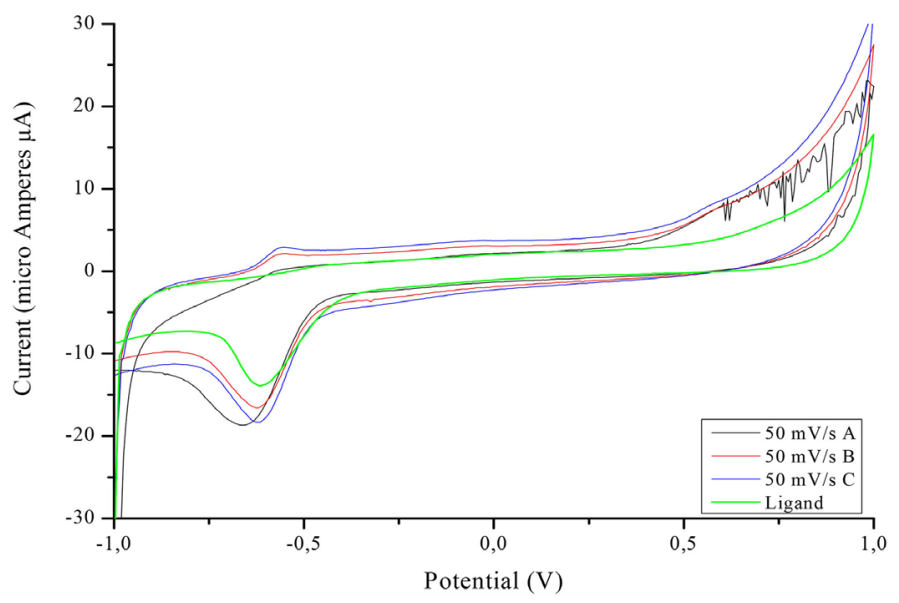

Figure 14. Cyclic voltammograms of the Fe-Schiff-base ligand complex electrodeposited onto a screen print carbon electrode in PBS at; performed at $50 \mathrm{mV} / \mathrm{s}$ for scans $\mathrm{A}, \mathrm{B}$ and $\mathrm{C}$.

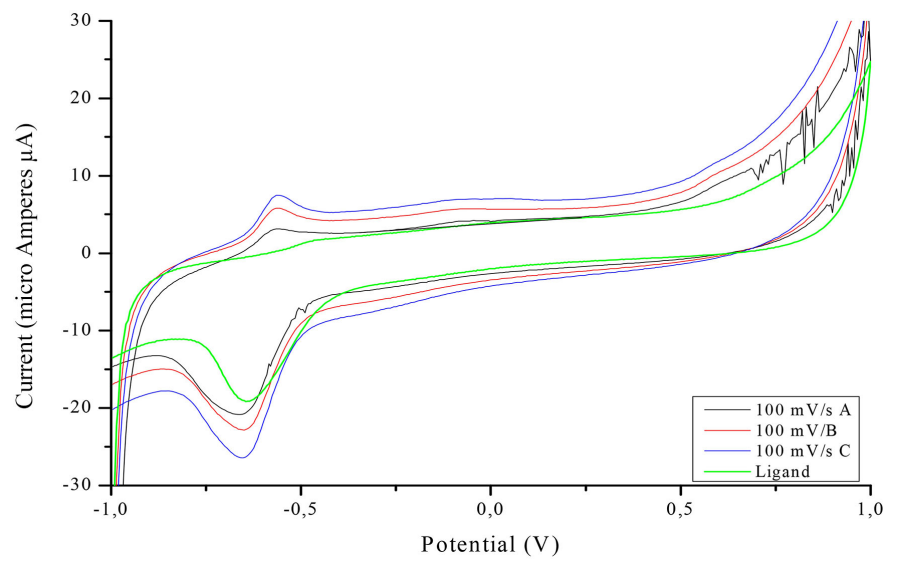

Figure 15. Cyclic voltammograms of the Fe-Schiff-base ligand complex electrodeposited onto a screen print carbon electrode in PBS at; performed at $100 \mathrm{mV} / \mathrm{s}$ for scans $\mathrm{A}, \mathrm{B}$ and $\mathrm{C}$.

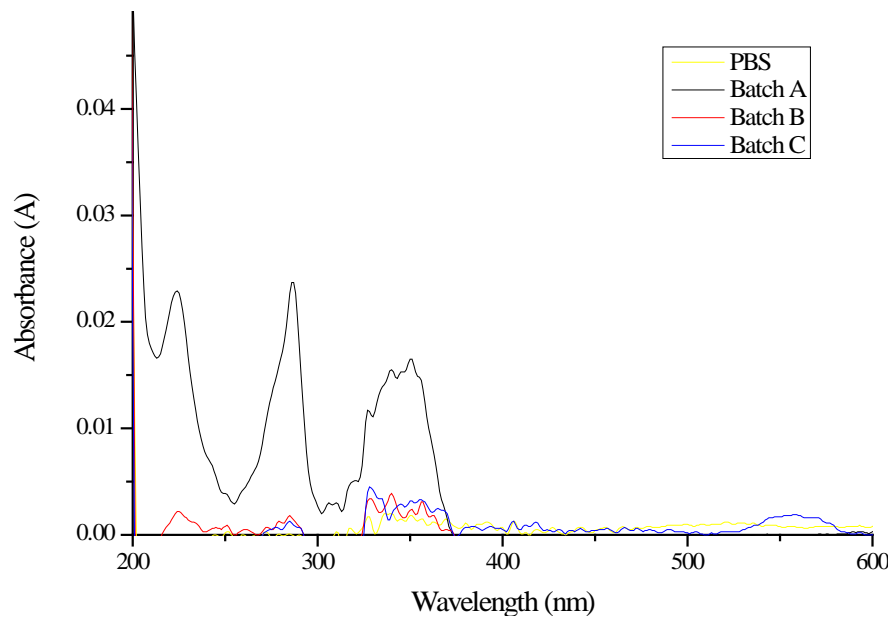

Figure 16. UV/Vis analysis of PB Selectrolyte after potential cycling, for each of the respective scan rate experiments. 


\section{Conclusion}

A novel heterocyclic metal conjugated Schiff-base was synthesized and studied with respect to its structure and electron transfer capabilities. Naphthalene diamine was found to be a suitable nucleophile for the Schiff-base synthesis in spite of its bulky nature. The Schiff-base was further successfully complexed with Fe to produce the Fe-Schiff-base ligand complex. Cyclic voltammetry confirmed that the electron transfer properties of denatured cytochrome-C deposited onto a Schiff-base ligand modified SPCE, were reproduced in the Fe-Schiff-base ligand complex electrodeposited directly onto the SPCE. The Fe-Schiff-base ligand complex displayed electron transfer properties similar to that of the denatured metalloprotein, studied in this work and presented a stable alternative for heme facilitated sensing applications, without the restriction of physiological $\mathrm{pH}$ conditions during application of the sensor to a sample solution.

\section{Acknowledgements}

The authors wish to acknowledge the National Research Foundation (South Africa) for research funding.

\section{Conflicts of Interest}

The authors declare no conflicts of interest regarding the publication of this paper.

\section{References}

[1] Chen, X.X., Ferrigno, R., Yang, J. and Whitesides, G.M. (2002) Redox Properties of Cytochrome c Adsorbed on Self-Assembled Monlayers: A Probe for Protein Confrmation and Orientation. Langmuir, 18, 7009-7015.

https://doi.org/10.1021/la0204794

[2] Hannibal, L., Tomasina, F., Capdevila, D.A., Demicheli, V., Totora, V., Alvarez-Paggi, D., Jemmerson, R., Murgida, D.H. and Radi, R. (2016) Alternative Conformations of Cytochrome c: Structure, Function, and Detection. Biochemistry, 55, 407-428. https://doi.org/10.1021/acs.biochem.5b01385

[3] Yue, H.J., Waldeck, D.H., Petrović, J. and Clark, R.A. (2006) The Effect of Ionic Strength on the Electron-Transfer Rate of Surface Immobilized Cytochrome c. Journal of Physical Chemistry B, 110, 5062-5072. https://doi.org/10.1021/jp055768q

[4] Hanrahan, K.L., Macdonald, S.M. and Roscoe, S.G. (1996) An Electrochemical Study of the Interfacial and Conformational Behaviour of Cytochrome $\mathrm{c}$ and Other Heme Proteins. Elecrrochimica Acta, 41, 2469-2419.

https://doi.org/10.1016/0013-4686(96)00035-7

[5] Bonanni, B., Alliata, D., Bizzarri, A.R. and Cannistraro, S. (2003) Topological and Electron-Transfer Properties of Yeast Cytochrome c Adsorbed on Bare Gold Electrodes. ChemPhysChem, 4, 1183-1188. https://doi.org/10.1002/cphc.200300784

[6] Bond, A.M., Hill, H., Allen, O., Komorsky-Lovrić, Š., Lovric, M., McCartby, M., Psalti, I. and Walton, N.J. (1992) Investigation of the Mass Transport Process in the Voltammetry of Cytochrome c at 4,4'-Bipyridyl Disulfide Modified Stationary and Rotated Macro- and Microdisk Gold Electrodes. The Journal of Physical Chemistry, 
96, 8100-8105. https://doi.org/10.1021/j100199a051

[7] Eguílaz, M., Agüí, L., Yáñez-Sedeño, P. and Pingarrón, J.M. (2010) A Biosensor Based on Cytochrome c Immobilization on a Poly-3-methylthiophene Multi-Walled Carbon Nanotubes Hybrid-Modified Electrode. Application to the Electrochemical Determination of Nitrite. Journal of Electroanalytical Chemistry, 644, 30-35. https://doi.org/10.1016/j.jelechem.2010.03.025

[8] Jancura, D., Stanicova, J., Palmer, G. and Fabian, M. (2014) How Hydrogen Peroxide Is Metabolized by Oxidized Cytochrome c Oxidase. Biochemistry, 53, 3564-3575. https://doi.org/10.1021/bi401078b

[9] Guo, C.X., Wang, J.F., Chen, X.Z., Li, Y.J., Wu, L.F., Zhang, J. and Tao, C.A. (2018) Construction of a Biosensor Based on a Combination of Cytochrome c, Graphene, and Gold Nanoparticles. Sensors (Basel, Switzerland), 19, 12-14.

https://doi.org/10.3390/s19010040

[10] Al-Amiery, A.A. (2012) Antimicrobial and Antioxidant Activities of New Metal Complexes Derived from (E)-3-((5-phenyl-1,3,4-oxadiazol-2-ylimino)methyl) naphthalen-2-ol. Medical Chemistry Research, 21, 3204-3213. https://doi.org/10.1007/s00044-011-9880-1

[11] Guzik, U., Hupert-Kocurek, K. and Wojcieszynska, D. (2014) Immobilization as a Strategy for Improving Enzyme Properties-Application to Oxidoreductases. Molecules, 19, 8995-9018. https://doi.org/10.3390/molecules19078995

[12] Grigoras, M., Vacareanu, L., Ivan, T. and Catargiu, A.M. (2013) Photophysical Properties of Isoelectronic Oligomers with Vinylene, Imine, Azine and Ethynylene Spacers Bearing Triphenylamine and Carbazole End-Groups. Dyes and Pigments, 98, 71-81. https://doi.org/10.1016/j.dyepig.2013.01.025

[13] Li, S.S., Ye, L., Zhao, W.C., Zhang, S.Q., Mukherjee, S., Ade, H. and Hou, J.H. (2016) Energy-Level Modulation of Small-Molecule Electron Acceptors to Achieve over 12\% Efficiency in Polymer Solar Cells. Advanced Materials, 28, 9423-9429. https://doi.org/10.1002/adma.201602776

[14] Caban, K., Offenhäusser, A. and Mayer, D. (2009) Electrochemical Characterization of the Effect of Gold Nanoparticles on the Electron Transfer of Cytochrome c. Physica Status Solidi (a), 206, 489-500. https://doi.org/10.1002/pssa.200880473

[15] Tanimura, R., Hill, M.G., Margoliash, E.M., Niki, K., Ohno, H. and Gray, H.B. (2002) Active Carboxylic Acid-Terminated Alkanethiol Self-Assembled Monolayers on Gold Bead Electrodes for Immobilization of Cytochromes c. Electrochemical and Solid-State Letters, 5, E67-E70. https://doi.org/10.1149/1.1517770

[16] Ward, M., Botha, S., Iwuoha, E. and Baker, P. (2014) Actuation Behaviour of a Derivatized Pyrrole Accordion Type Polymer. International Journal of Electrochemical Science, 9, 4776-4792.

[17] Xavier, A. and Srividhya, N. (2014) Synthesis and Study of Schiff-base Ligands. IOSR Journal of Applied Chemistry, 7, 6-15. https://doi.org/10.9790/5736-071110615

[18] Muzammil, K., Trivedi, P. and Khetani, D.B. (2015) Synthesis and Characterization of Schiff-base m-Nitro Aniline and Their Complexes. Research Journal of Chemical Sciences, 5, 52-55.

[19] Simionescu, C.I., Grigoras, M., Cianga, I. and Olaru, N. (1998) Synthesis of New Conjugated Polymers with Schiff-base Structure Containing Pyrrolyl and Naphthalene Moieties and HMO Study of the Monomers Reactivity. European Polymer Journal, 34, 891-898. https://doi.org/10.1016/S0014-3057(97)00226-7

[20] Faizul, A., Satendra, S., Lal, K.S. and Om, P. (2007) Synthesis of Schiff Bases of 
Naphtha[1,2-d]thiazol-2-amine and Metal Complexes of 2-(2'-hydroxy)benzylide neaminonaphthothiazole as Potential Antimicrobial Agents. Journal of Zhejiang University Science B, 8, 446-452. https://doi.org/10.1631/jzus.2007.B0446

[21] Barbon, S.M., Staroverov, V.N. and Gilroy, J.B. (2015) Effect of Extended $\pi$ Conjugation on the Spectroscopic and Electrochemical Properties of Boron Difluoride Formazanate Complexes. Journal of Organic Chemistry, 80, 5226-5235. https://doi.org/10.1021/acs.joc.5b00620

[22] Isaiah, A.A. and Collins, U.I. (2013) A Theoretical Study on the Effect of Substituents on the Properties of Pyrrole and Thiophene. New York Science Journal, 6, 99-105.

[23] Sek, D., Siwy, M., Bijak, K., Filapek, M., Malecki, G., Nowak, E.M., Sanetra, J., Jarczyk-jedryka, A., Laba, K. and Lapkowski, M. (2015) Optical and Electrochemical Properties of Novel Thermally Stable Schiff Bases Bearing Naphthalene Unit. Journal of Electroanalytical Chemistry, 751, 128-136. https://doi.org/10.1016/j.jelechem.2015.05.040

[24] Cheng, J.H., Wei, K.Y., Ma, X.F., Zhou, X.G. and Xiang, H.F. (2013) Synthesis and Photophysical Properties of Colorful Salen-Type Schiff Bases. Journal of Physical Chemistry C, 117, 16552-16563. https://doi.org/10.1021/jp403750q

[25] Doddi, G., Illuminati, G., Mencarelli, P. and Stegel, F. (1976) Nucleophilic Substitution at the Pyrrole Ring. Comparison with Furan, Thiophene, and Benzene Rings in Piperidinodenitration. Journal of Organic Chemistry, 41, 2824-2826. https://doi.org/10.1021/jo00879a008

[26] Liu, Z.D., Liu, D.Y. and Hider, R.C. (2002) Iron Chelator Chemistry. In: Iron Chelation Therapy. Advances in Experimental Medicine and Biology, Springer, Boston, 141-142. https://doi.org/10.1007/978-1-4615-0593-8 8

[27] Hawrelak, E.J., Bernskoetter, W.H., Lobkovsky, E., Yee, G.T., Bill, E. and Chirik, P.J. (2005) Square Planar vs Tetrahedral Geometry in Four Coordinate Iron(II) Complexes. Inorganic Chemistry, 44, 3103-3111. https://doi.org/10.1021/ic048202+

[28] Yousif, E., Majeed, A., Al-Sammarrae, K., Salih, N., Salimon, J. and Abdullah, B. (2017) Metal Complexes of Schiff Base: Preparation, Characterization and Antibacterial Activity. Arabian Journal of Chemistry, 10, S1639-S1644. https://doi.org/10.1016/j.arabjc.2013.06.006

[29] Sumrra, S.H., Ibrahim, M., Ambreen, S., Imran, M., Danish, M. and Rehmani, F.S. (2014) Synthesis, Spectral Characterization, and Biological Evaluation of Transition Metal Complexes of Bidentate N, O Donor Schiff Bases. Bioinorganic Chemistry and Applications, 10, 1-10. https://doi.org/10.1155/2014/812924

[30] Tümer, M., Akgün, E., Toroğlu, S., Kayraldiz, A. and Dönbak, L. (2008) Synthesis and Characterization of Schiff-base Metal Complexes: Their Antimicrobial, Genotoxicity and Electrochemical Properties. Journal of Coordination Chemistry, 61, 2935-2949. https://doi.org/10.1080/00958970801989902

[31] Chaudhary, N.K. and Mishra, P. (2017) Metal Complexes of a Novel Schiff-base Based on Penicillin: Characterization, Molecular Modeling, and Antibacterial Activity Study. Bioinorganic Chemistry and Applications, 2017, Article ID: 6927675. https://doi.org/10.1155/2017/6927675

[32] Beyazit, N., Çobanoğlu, S. and Demetgül, C. (2017) Metal Complexes of Perimidine and Schiff-base Ligands Bearing Both Naphthalene and Chromone Moieties: Synthesis and Catalytic Activity. Bulgarian Chemical Communications, 49, 115-121.

[33] Tümer, M. (2007) Polydentate Schiff-Base Ligands and Their Cd(II) and Cu(II) Metal Complexes: Synthesis, Characterization, Biological Activity and Electro- 
chemical Properties. Journal of Coordination Chemistry, 60, 2051-2065. https://doi.org/10.1080/00958970701236727

[34] Khalil, M.M.H., Ismail, E.H., Mohamed, G.G., Zayed, E.M. and Badr, A. (2012) Synthesis and Characterization of a Novel Schiff-base Metal Complexes and Their Application in Determination of Iron in Different Types of Natural Water. Open Journal of Inorganic Chemistry, 2, 13-21. https://doi.org/10.4236/ojic.2012.22003

[35] Grosvenor, A.P., Kobe, B.A., Biesinger, M.C. and Mcintyre, N.S. (2004) Investigation of Multiplet Splitting of Fe 2p XPS Spectra and Bonding in Iron Compounds. Surface and Interface Analysis, 36, 1564-1574. https://doi.org/10.1002/sia.1984

[36] Sparrow, T.G., Williams, B.G., Rao, C.N. and Thomas, J. (1984) L3/L2 White-Line Intensity Ratios in the Electron Energy-Loss Spectra of 3d Transition-Metal Oxides. Chemical Physical Letter, 108, 547-550. https://doi.org/10.1016/0009-2614(84)85051-4

[37] Al-Salih, T.E. and Al-Taha, R.W. (2014) Cyclic Voltammerty Study of Schiff-Base Ligand and the Effect of Groups Substitutes on Potential and Electroactivity (C). Der Pharma Chemica, 6, 42-50.

[38] Bott, A.W. (1999) Characterization of Chemical Reactions Coupled to Electron Transfer Reactions Using Cyclic Voltammetry. Current Separations, 18, 9-16.

[39] Mostany, J. and Scharifker, B.R. (1997) Impedance Spectroscopy of Undoped, Doped and Overoxidized Polypyrrole Films. Synthetic Metals, 87, 179-185. https://doi.org/10.1016/S0379-6779(97)80105-1

[40] Frew, J.E. and Hill, H.A. (1988) Direct and Indirect Electron Transfer between Electrodes and Redox Proteins. European Journal of Biochemistry, 172, 261-269. https://doi.org/10.1111/j.1432-1033.1988.tb13882.x

[41] Murgida, D.H. and Hildebrandt, P. (2005) Redox and Redox-Coupled Processes of Heme Proteins and Enzymes at Electrochemical Interfaces. Physical Chemistry Chemical Physics, 7, 3773-3784. https://doi.org/10.1039/b507989f

[42] Sagara, T., Niwa, K., Sone, A., Niki, K. and Hinnen, C. (1990) Redox Reaction Mechanism of Cytochrome c at Modified Gold Electrodes. Langmuir, 6, 254-262. https://doi.org/10.1021/la00091a042

[43] Eddowes, M.J., Hill, H. and Allen, O. (1979) Electrochemistry of Horse Heart Cytochrome c. Journal of the American Chemical Society, 101, 4461-4464. https://doi.org/10.1021/ja00510a003

[44] Abass, A.K. and Hart, J.P. (2001) Direct Electrochemistry of Cytochrome c at Plain and Membrane Modified Screen-Printed Carbon Electrodes. Electrochimica Acta, 46, 829-836. https://doi.org/10.1016/S0013-4686(00)00668-X

[45] Latimer, W.M. and Hildebrand, J.H. (1944) Iron. In: Reference Book of Inorganic Chemistry, The Macmillan Company, New York, 380-399.

[46] Bhatt, V. (2016) Thermodynamics and Kinetics of Complex Formation. In: Essentials of Coordination Chemistry, Academic Press, Cambridge, 111-137. https://doi.org/10.1016/B978-0-12-803895-6.00004-5

[47] Collins, M.J., Ray, K. and Que, L. (2006) Electrochemical Generation of a Nonheme Oxoiron(IV) Complex. Inorganic Chemistry, 45, 8009-8011. https://doi.org/10.1021/ic061263i 